\title{
Evaluating Scuffing Failure in Dry Sliding Conditions of Monolayer Chromium Piston Ring/Bulk Grey Cast Iron Liner Interface
}

\author{
Syed Danish Fayaz and Mohammad Farooq Wani \\ Tribology Laboratory, Department of Mechanical Engineering, National Institute of Technology Srinagar, \\ Hazratbal, Kashmir (J\&K) India 190006 \\ *Corresponding author: Syed Danish Fayaz (danish_06phd13@nitsri.net)
}

Manuscript received 07 October 2019; accepted 08 December 2019; published 15 January 2020

\begin{abstract}
This research reports the scuffing failure phenomenon of piston ring-cylinder liner in pilot state bench tests. Initially, microhardness evaluation of chromium sprayed piston rings of functionally graded Aluminium A390 piston was conducted using a Vickers hardness Indenter following ASTM E-384 standard. The tribological characterization for dry sliding, simulating lubrication starvation was evaluated using reciprocating Universal Tribometer. For surface morphology and allied surface characterization, Energy Dispersive X-Ray spectroscopy integrated Scanning Electron Microscope was used. Substantially large volumes of wear depicting abnormal wear have been observed on the tribo-conjugate grey CI cylinder liner surfaces in sliding with chromium coating on SAE9254 grade steel substrate. This can be attributed to the considerable hardness gradient of tribopair in conjugation. With chromium coating having a conspicuous hardness edge over the CI cylinder liner, the extrusion and ploughing of the liner surface depict the abnormality in wear. The Coefficient of Friction (COF) under dry sliding with stepped load increments showed an unsteady state of friction and this performance is underrated for operation of any tribological system.
\end{abstract}

\section{Keywords}

piston ring, cylinder liner, scuffing, microhardness

\section{Introduction}

The study of overall efficiency and exhaust emissions are the preconditions impelling causes in modern-day Internal Combustion (IC) engine development. The overall efficiency can be tailored by various alleviative approaches within a multi-faceted framework. Considerably, the diminution in mass and balancing inertia without disturbing the robustness. Noise damping and vibrational refinement form a stringent dimension of this framework [1]. Further, the cutdown in the thermal and miscellaneous parasitic losses is a key objective in modern-day research and development. While as thermal losses constitute for $55-65 \%$ of the total indicative power while as the miscellaneous parasitic load comprising supercharging and pumping, consume further $15-20 \%$ of indicative power from the drive line $[2,3]$.

Piston rings find their utility in exhaust gas seal of the clearance between the piston and the cylinder liner for efficient Internal Combustion (IC) engine operation. The piston ringcylinder liner interface in reciprocating action is subjected to continuous wearing out due to consistent asperity interactions subjected to high temperature and extensive loading [4]. Thus, the performance and reliability of such heavy loaded engine assemblies rely on the mating surface topographies and associated tribological interactions. It is hence indispensable to investigate the tribological behaviour of liner-ring triboconjugates susceptible to scuffing under lubrication starvation and intended remedies for effective scuffing prevention [5]. This emergence leads in the development of new surface coatings and modifications with substantial wear attributes under exigent operational conditions.

Scuffing results when the rise of friction between tribocontacts approaches a catastrophic state, leading to severe welding, damage and dislodging of contact surfaces to an extent that they become potentially unserviceable. This is governed by a combination of operating conditions which include; surface roughness, temperature, lubrication, load and intrinsic material characteristics. They contribute equally in the formation and dislodging of lubricant film during actual working cycles of an engine [6]. In the absence of any lubrication film or synergetic tribo-films the contact area tends to 'Weld' together. This weld however isn't too strong to stop the relative sliding between cylinder liner and piston ring and hence gets completely dislodged resulting in material transfer from the softer counterpart while adhering to the harder surface [7].

High operating engine temperatures often anticipate in 
Table 1 Standard composition, mechanical \& thermal properties of ISO R185220 grade grey cast iron

\begin{tabular}{|c|c|c|c|c|c|c|c|}
\hline $\mathrm{C}(\%)$ & $\mathrm{Si}(\%)$ & $\mathrm{S}(\%)$ & $\mathrm{P}(\%)$ & $\mathrm{Mn}(\%)$ & $\mathrm{Ni}(\%)$ & $\mathrm{Cr}(\%)$ & Others \\
\hline 3.4 & 2.3 & 0.06 & 0.5 & 0.8 & - & 0.4 & $\operatorname{Rest~Fe}$ \\
\hline
\end{tabular}

Ultimate Tensile Strength $(\mathrm{UTS})=260 \mathrm{MN} / \mathrm{m}^{2}$, Brinell Hardness $(\mathrm{BHN})=250$ Modulus of Elasticity $(\mathrm{MOE})=83-124 \mathrm{MN} / \mathrm{m}^{2}$, Thermal Conductivity $(\mathrm{K})=11 \times 10^{-6} /{ }^{\circ} \mathrm{C}$

'Hot Scuffing'. Under certain conditions of load, sliding and lubrication, the temperature rises to a critical state where the formation of lubricant film ceases and any formed lubricant film collapses, leading to a catastrophic frictional rise. This continuous thermal feedback to the contact area leads to 'Scuffing' of piston ring-cylinder liner conjunction [7]. With the changes in engine design and materials, though the engine performance has significantly increased with reduced emissions, the increased serviceability and scuffing failures can't be ruled out. Wang et.al. indicated damage to top piston ring before the actual scuffing failure [8]. Enthoven et. al. and Barrell et. al. found lubricant evaporation as the main reason of engine scuffing $[7,9]$. In most of the research works pertaining to the scuffing bench tests, the stepped normal loading with constant sliding speed and temperature, thus evaluating a critical load where scuffing occurs [10].

Significantly, many surfaces engineered topographies, treatments and coatings have been applied to the piston ringcylinder liner interface to improve the tribological characteristics of surface asperity contacts [11]. The scale of such engineered coatings and surface treatments used in reciprocating assemblies are widespread, cover diverse compositions and deposition techniques. the surface treatments applied to cylinder liners include laser texturing, honing, surface indentation, while as the surface tailoring of piston rings include deposition techniques such as, thermal spraying, galvanic deposition, cathodic arcdeposition, laser surface alloying and surface treatments used are shock hardening, surface nitriding, surface hardening with iron-nitride structure grading on ring surface region [12-14].

Microhardness is considered indicative of wear resistance of materials. Although many research works have disapproved the bridging of microhardness to certain forms of wear, which include abrasive wear and erosive wear [15]. At the same time, hardness as a material characteristic influences friction and wear. Though hardness as a bulk property relates to most of the materials, the microhardness results are beneficial in ascribing the phase configuration, phase inclusions, under surface defects, etc [16]. To the engineered coatings, microhardness evaluates their superiority in bulk property contrasting the deposition substrate. This study necessitates the bridging of the microhardness to tribological characterization for piston ring-cylinder liner tribo-contacts under lubrication starvation. Further, material characterization is evaluated with techniques including, Energy Dispersive X-Ray spectroscopy (EDX) integrated Scanning Electron Microscopy (SEM).

\section{Experimental}

\subsection{Materials and material composition}

The piston ring samples utilized in this tribological study are from an actual heavy-duty compression ignited engine. The piston ring is a top compression ring with an inside bevel, top and a $9.4 \mathrm{~cm}$ of the nominal cylinder bore. The contact is purely conformal, to ensure any misalignment and contact compatibility the piston ring was cut into approximately 13 pieces. The cylinder liner is an ISO R185220 grade grey Cast
Iron (CI) with typical standard composition and properties (Mechanical \& Thermal) given in Table 1. Initially, each liner was sectioned into a $25.4 \mathrm{~mm} \times 50.8 \mathrm{~mm}$ section, but this would have amounted to large scale material wastage. Instead, 12.18 $\mathrm{mm} \times 50 \mathrm{~mm}$ sections were from each liner were used instead. The surface of the cylinder liner is textured with plateau honing by diamond hones subtending a hone angle of $45^{\circ}$ across the cross hatches. The honing operation ploughs crosshatches that behave as lubricant reservoirs during engine working cycles. For all the machining and specimen operations, the surfaces of both the tribo-elements were preserved to retain their originality in surface roughness and proximity of surface patterns. The ring has plasma sprayed chromium coating of $42 \mu \mathrm{m}$ thickness with textured spherical micro dimples. The coating thickness was measured by Leica layer thickness microscopy using Standard ASTM B487 test as depicted in Fig. 2(a).

The ring segments were fastened into a manufactured conformal ring holder, secured into the reciprocating arm of Universal Tribometer as shown in Figure 1. The conspicuous crosshatch honing pattern is evident in Fig. 2(b) which corresponds to grey $\mathrm{CI}$ liner samples, while as textured spherical micro-dimples can be seen in Fig. 2(c) which correspond to chromium coating of ring samples. Figure 3 depicts the cylinder inscribed in a cylindrical cavity forming a conformal contact. The liner samples are stationary table mounted on the test rig with an embedded heating element and piezoelectric sensors. The surface of the grey CI cylinder liner showing standard honing topology is depicted by SEM micrograph at a magnification of 100x and shown in Fig. 4 (a). The cross-hatch texture grooves are visible, which serve the purpose of lubricant retention during each engine cycle. Further, the fair dispersion of graphite flakes in the ferrous matrix could be seen in the micrograph and is confirmed by the spectra of elemental carbon using EDX verifying the similar results by Kaleicheva et. al [17]. Figure 4(b) shows the EDX spectra of grey CI cylinder liner with the identified elemental composition shown in Fig. 5.

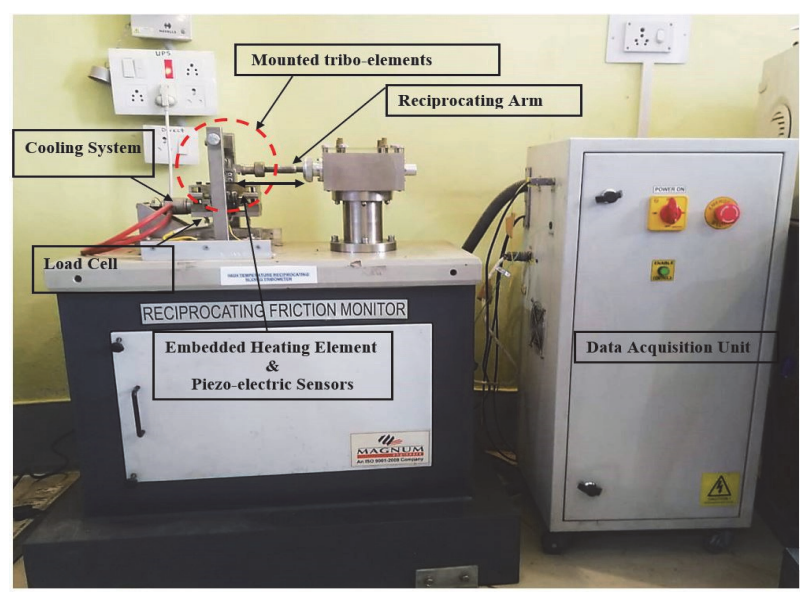

Fig. 1 Schematic of ring on liner configuration mounted on universal tribometer 

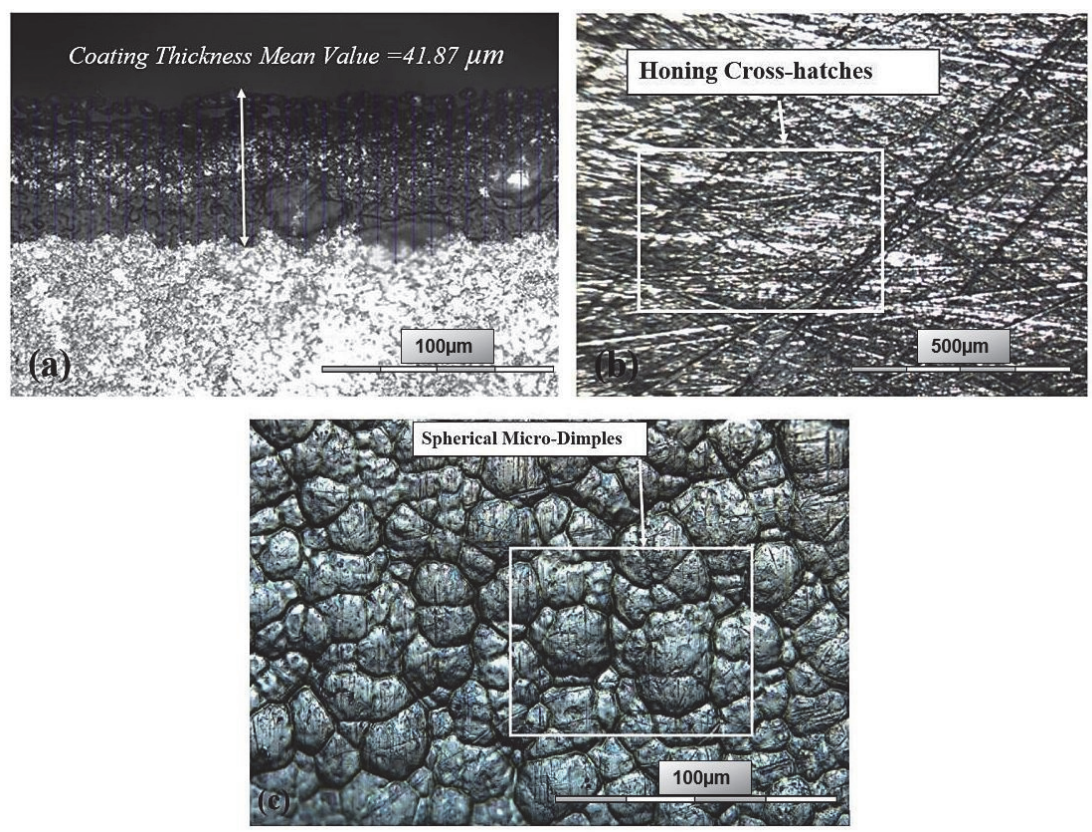

Fig. 2 (a) Magnified microscopic image of coating thickness measurement, (b) Microscopic image of the liner surface, (c) Microscopic image of the ring surface
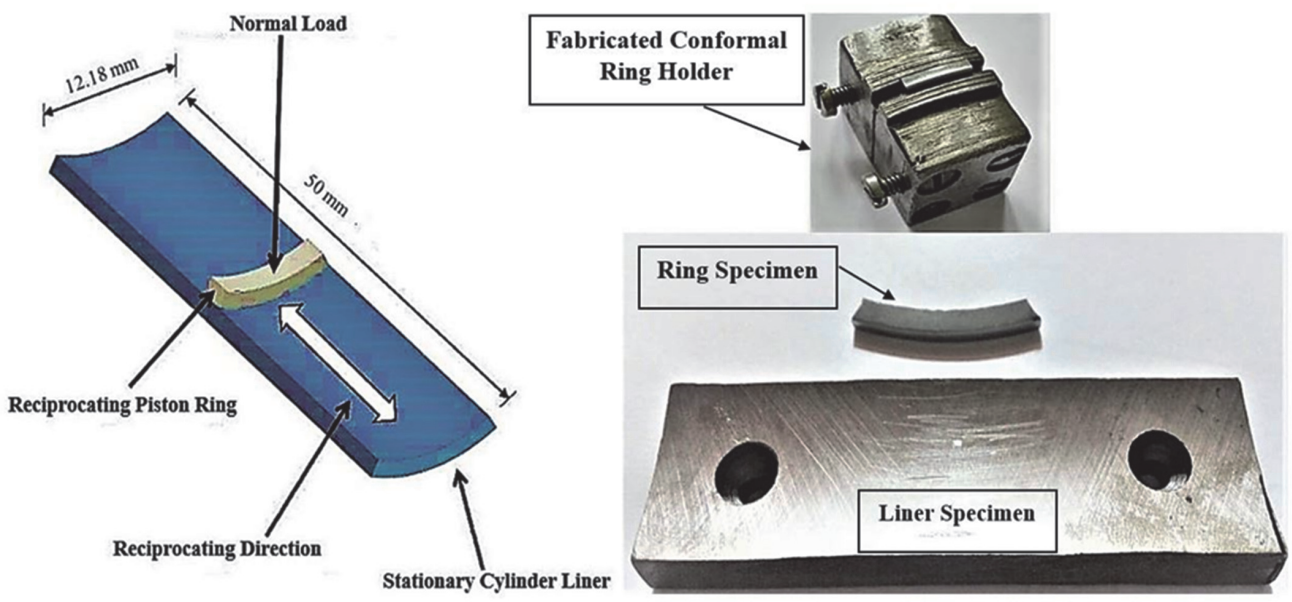

Fig. 3 Conformal liner-ring contact, ring and liner sections
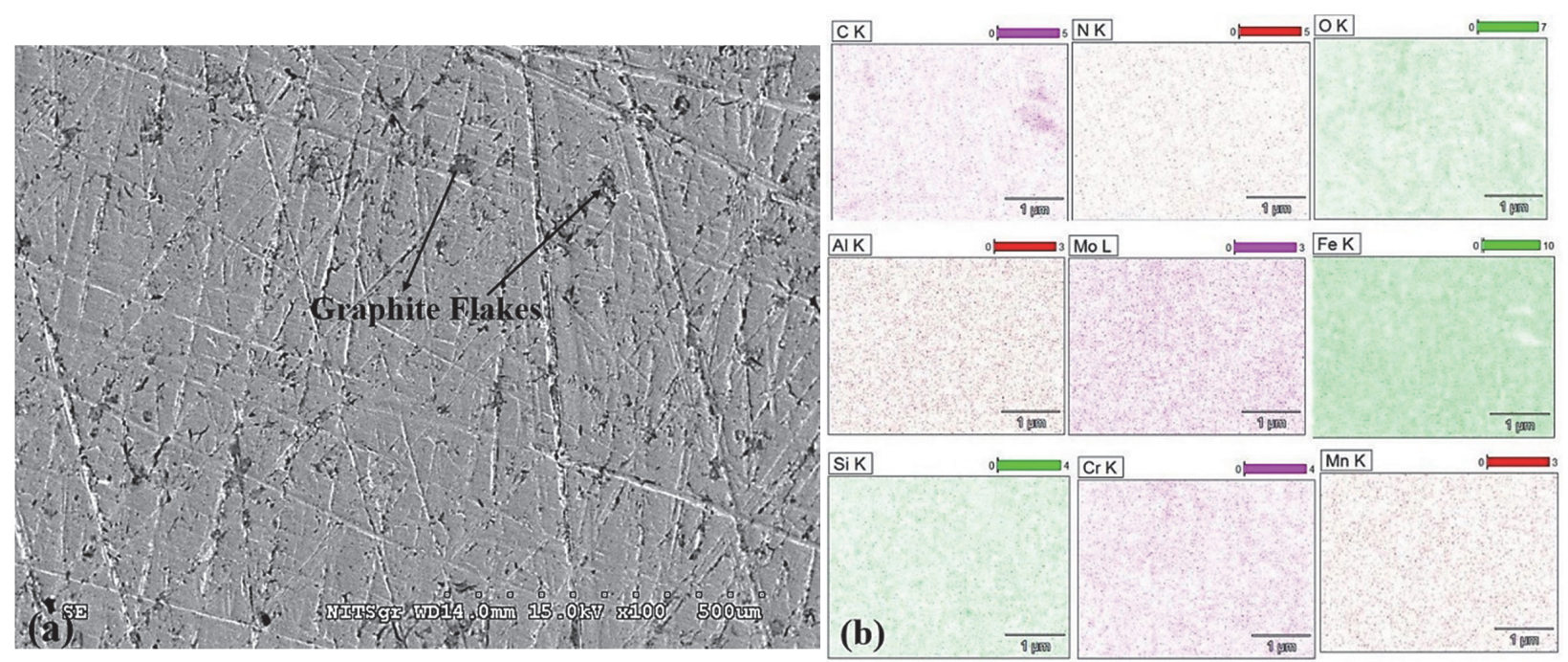

Fig. 4 (a) SEM micrograph of grey CI cylinder liner, (b) Elemental spectra of grey CI liner 


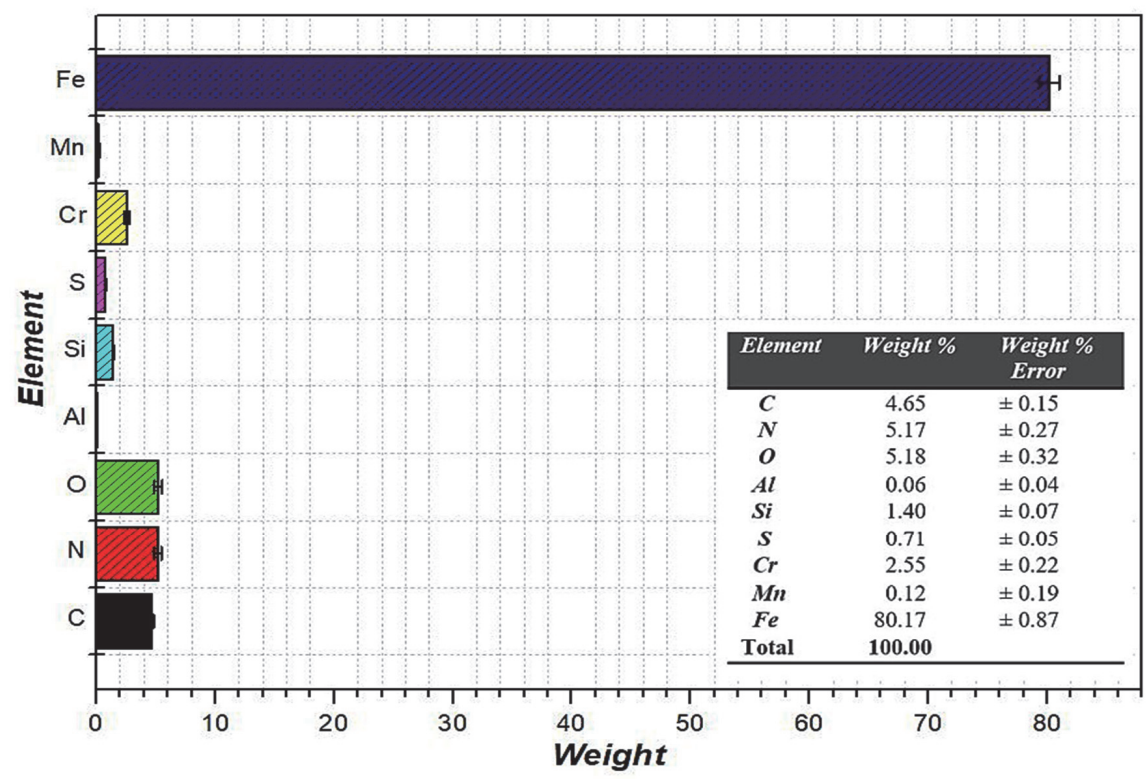

Fig. 5 Elemental composition of Grey CI cylinder liner identified by EDX
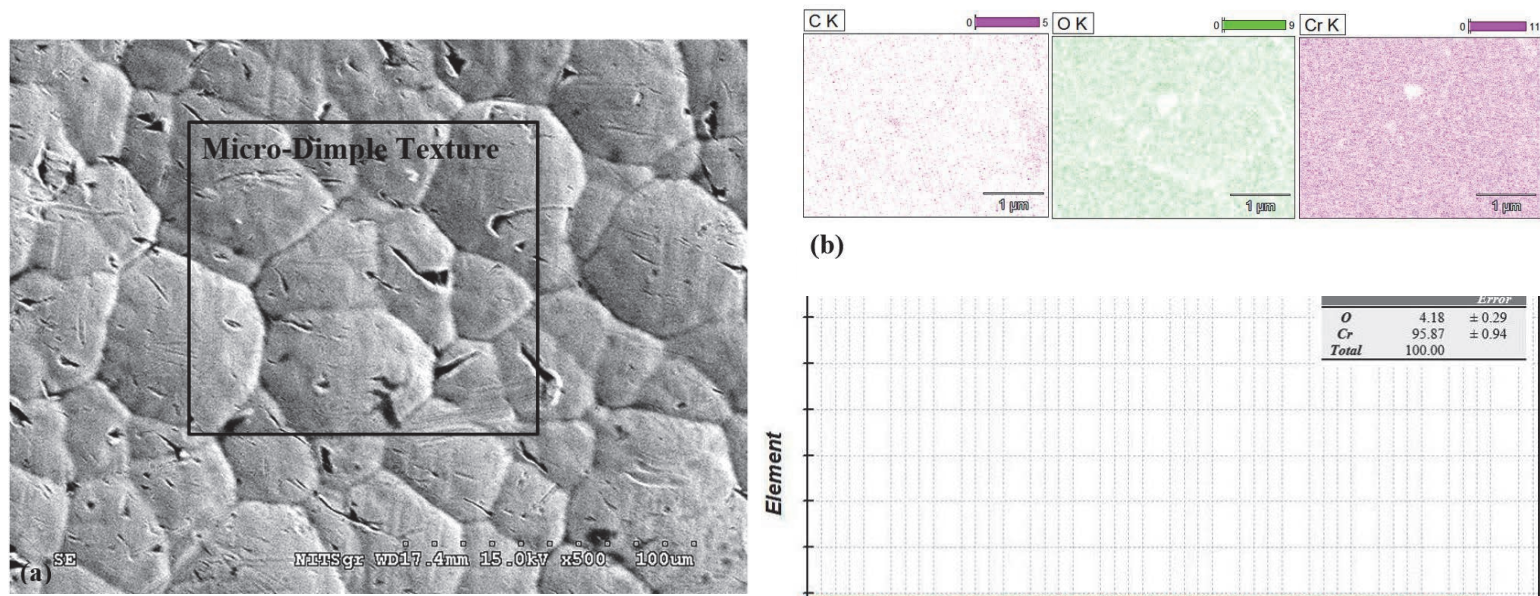

(b)

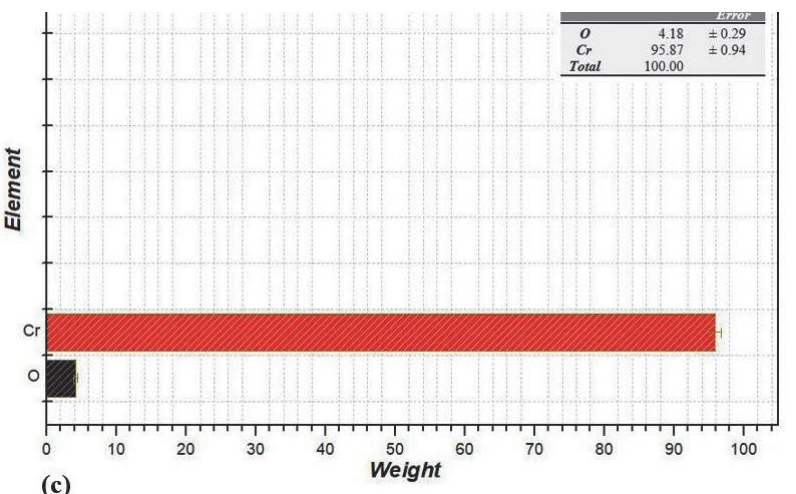

(c)

Fig. 6 (a) SEM micrograph of chrome coated piston ring, (b) Elemental spectra of chrome coated compression ring, (c) Elemental composition of chromium coating identified by EDX

Secondly, the microstructure, surface topology, and morphology of chromium coating surface were investigated using SEM. Semi-quantitative analysis of chemical composition was measured with EDX equipped in SEM. The SEM micrograph of the coating surface is depicted in Fig. 6(a). At a higher magnification of 500x, the micrograph shows a singlephase chromium microstructure with micro-dimple texture. No grain boundaries are evident, however under plastic deformation, crack initiation and propagation may progress through the dimple channels and scratches on the surface hence verified with the similar studies of Wei [18]. The elemental spectra can be seen in Fig. 6(b). The chemical composition verified by elemental spectra shows the presence of elemental chromium in binding with elemental oxygen, thus confirming the presence of chromium Oxide $\left(\mathrm{Cr}_{2} \mathrm{O}_{3}\right)$ throughout the single-phase microstructure [19]. Figure 6(b) depicts the EDX spectra of grey CI cylinder liner with the identified elemental composition shown in Fig. 6(c).

\section{Results and discussion}

3.1 Micro-hardness studies

Vickers Indentation based microhardness following ASTM E-384 Standard tests were performed on the chromium coating and bulk material of grey CI Cylinder liner at specific loads on Falcon INNOVATEST 500 hardness tester [20]. Repeatability, load accuracy boast of $<1 \%$ at each individual indentation load and dwell time of 10 seconds was ensured for each indentation. The indentation loads of $0.1 \mathrm{kgf}(0.98 \mathrm{~N}), 0.2 \mathrm{kgf}(1.96 \mathrm{~N}), 0.3 \mathrm{kgf}$ $(2.94 \mathrm{~N}), 0.5 \mathrm{kgf}(4.90 \mathrm{~N}), 1 \mathrm{kgf}(9.8 \mathrm{~N}), 2 \mathrm{kgf}(19.6 \mathrm{~N})$ were used for evaluation. The resultant indentations of chromium coating imaged with optical microscope at 40x magnification, integrated 


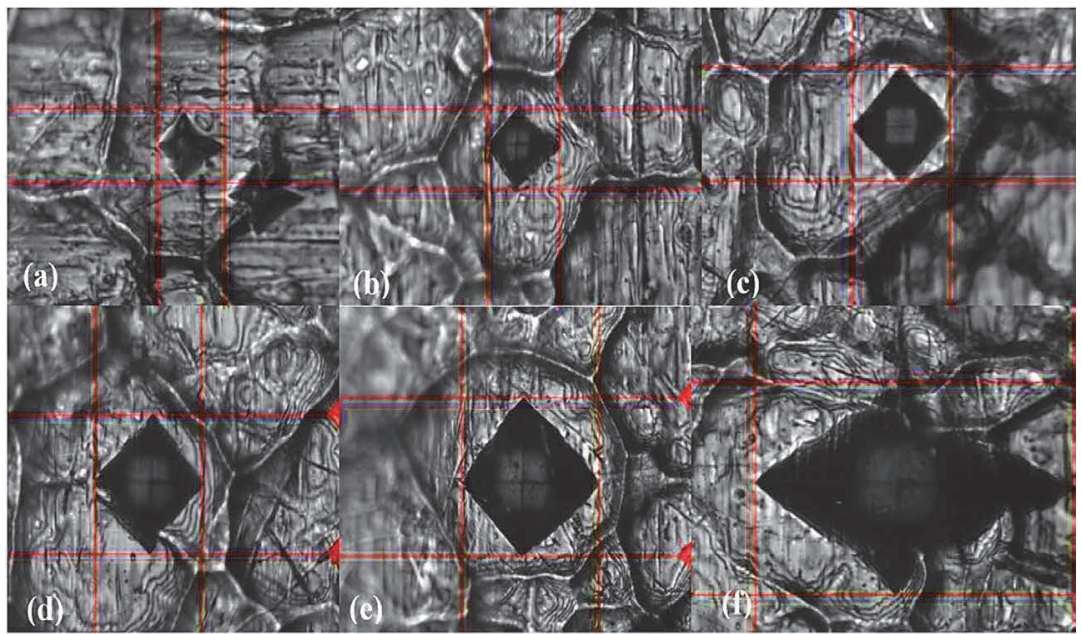

Fig. 7 Representative optical microscopic images depicting indents on chromium coating at indentation loads of (a) $0.98 \mathrm{~N}$, (b) $1.96 \mathrm{~N}$, (c) $2.94 \mathrm{~N}$, (d) $4.90 \mathrm{~N}$, (e) $9.8 \mathrm{~N}$, (f) $19.6 \mathrm{~N}$

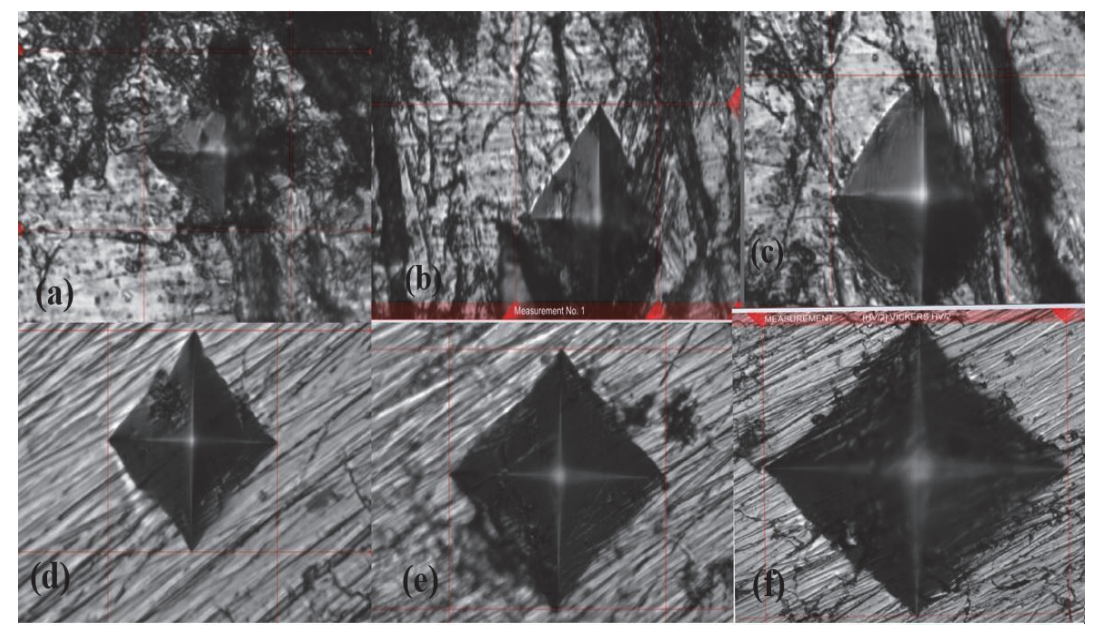

Fig. 8 Representative optical microscopic images depicting indents on Grey CI cylinder liner bulk at indentation loads of (a) $0.98 \mathrm{~N}$, (b) $1.96 \mathrm{~N}$, (c) $2.94 \mathrm{~N}$, (d) $4.90 \mathrm{~N}$, (e) $9.8 \mathrm{~N}$, (f) $19.6 \mathrm{~N}$

into the hardness tester are shown in Fig. 7(a-f), while as the imaged micro-indents of the gey $\mathrm{CI}$ liner bulk are depicted in Fig. 8(a-f).

The comparative Vickers Hardness (HV) results corresponding to cylinder liner and piston ring tribo-elements at specified indentation loads are shown in Fig. 9 (a-b). For, chromium coating of piston ring, there is a steep increment in the $\mathrm{HV}$ value for the first loading step starting from 0.98 $\mathrm{N}$ to $1.98 \mathrm{~N}$ which imputes Vickers hardness as a function of indentation load. During the two next consecutive steps of indentation loading, a small-scale decrement in the $\mathrm{HV}$ values is observed, which is attributed to the Indentation Size Effect (ISE) [21, 22]. ISE is the substantial decrease of hardness values with increasing indentation loads and a proportionate decrease in the indentation depth. The hardness curve between loads, 4.90 $\mathrm{N}$ to $9.8 \mathrm{~N}$ show a cumulative increase in apparent $\mathrm{HV}$ values, phenomenal to Hardness-Load dependency. In the last stage of microhardness tests for piston ring and load increment to 9.8 $\mathrm{N}$, ISE remains dominant with a steep decrement in hardness to $813 \mathrm{HV}$.

In contrast, the microhardness behaviour for bulk material of cylinder liner showed an apparent dominance of ISE for the first step of indentation loading in the range from $0.98 \mathrm{~N}$ to $1.98 \mathrm{~N}$. A sharp increment, depicting Load dependency is prerogative of next increment in indentation load of $1.96 \mathrm{~N}$. At indentation load of $2.94 \mathrm{~N}$ and for first half of the indentation dwelling, load dependency remains dominant while as the next dwelling state of indentation, ISE remains dominant. The last two steps of indentation loading in the range of $4.90 \mathrm{~N}$ to $9.8 \mathrm{~N}$ and $9.8 \mathrm{~N}$ to $19.6 \mathrm{~N}$ respectively are dominated by ISE.

The average hardness value for chromium coating deposited on the piston ring is $1002 \mathrm{HV}$, while as for bulk CI cylinder liner the average hardness value of $266 \mathrm{HV}$ is obtained. For most of the indentation steps to the cylinder liner surface, the dominance of ISE is evident and is attributed to the heterogeneity in the microstructure, grain distribution in the iron matrix and processing constraints such as casting defects, solidification time, cooling rate, etc.

Given all that, it can be inferred that the homogeneity in microstructure is vital in determining the hardness of a material. This led to the microhardness superiority of chrome coated piston ring over bulk material grey CI liner. Secondly, the size of the indents showed a wider margin between the triboelements. The average size of indents for chromium coated ring specimens was approximately 3 times less to the indent sizes on bulk grey CI liner. This can thus be attributed to the higher 


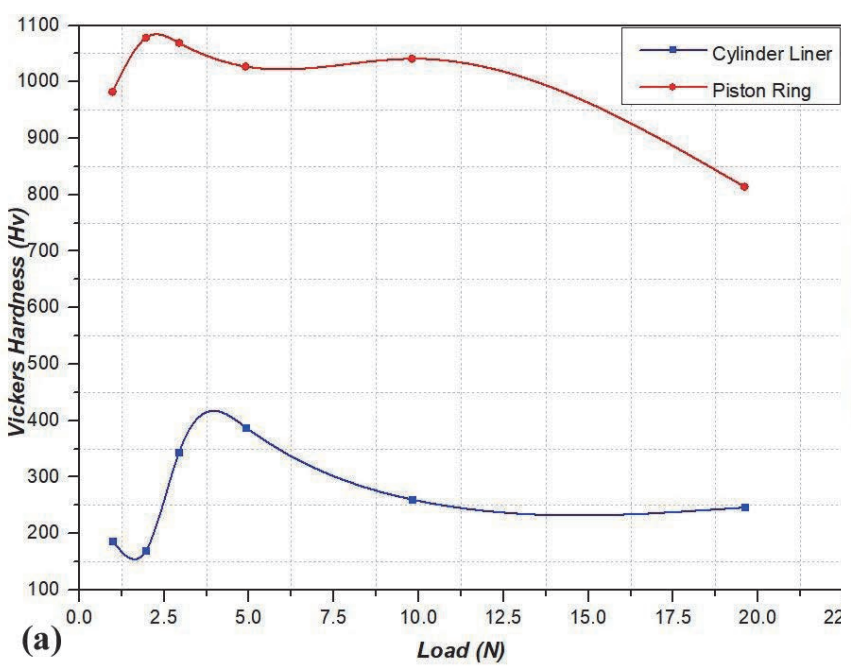

Fig. 9 (a) Comparative hardness-load variation data plot of piston ring/cylinder liner tribo-elements at different indentation loads, (b) Bar graph highlighting corresponding HV values for both the tribo-elements strength and low tendency to plastic deformation of chromium coating contrasting the vice-versa behaviour of CI liner and similar behaviour is depicted in the work of Marcinkowsi et. al. [23].

\subsection{Friction}

The Coefficient of Friction (COF) as a function of cumulative time for dry sliding simulating lubrication starvation was continuously monitored and evaluated at normal loads of 20 $\mathrm{N}, 40 \mathrm{~N}, 60 \mathrm{~N}$ on Magnum Universal Tribometer conforming to ASTM G99 Standard [24]. The results of the COF as a function of cumulative sliding time for the cited sliding condition is depicted in Fig. 10. The frictional tribotests were conducted at a temperature of $250^{\circ} \mathrm{C}$, reciprocating frequency of $10 \mathrm{~Hz}$, test time of 4 minutes and a stroke length of $2 \mathrm{~mm}$ respectively. In order to avoid any loss of content during data acquisition on the test rig, the reciprocating frequency was maintained at a lower value of $10 \mathrm{~Hz}$. It is pertinent to mention that any increment in the reciprocating frequency during experimentation significantly implies a fall in the mean force, following a drop in frictional data acquisition and ultimately an errored resonant response [25]. Hence, a constant reciprocating frequency and

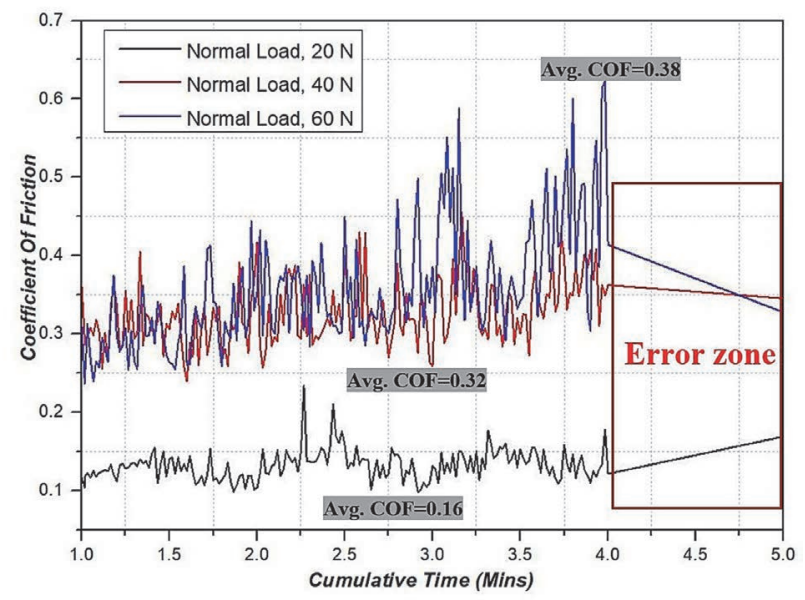

Fig. 10 Coefficient of friction as a function of cumulative time for dry sliding under variable loads of $20 \mathrm{~N}, 40 \mathrm{~N}, 60 \mathrm{~N}$

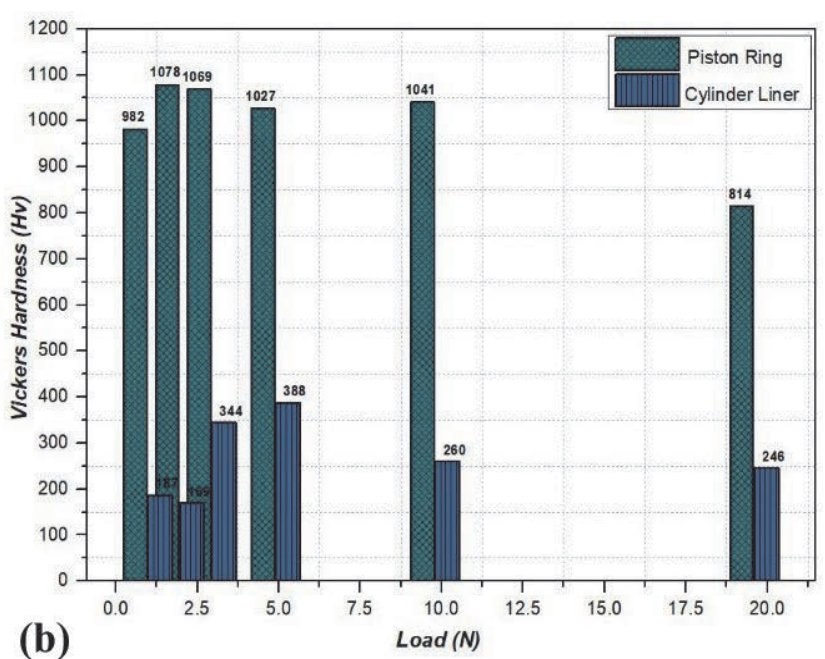

repeatability with at least three sets of experiments is ensured. A computational error of 1 minute is observed and all the obtained results have been oriented to first 3 minutes of sliding. A continuous steady fluctuation of COF can be seen in the dry sliding at baseload of $20 \mathrm{~N}$ throughout the tribotests and is attributed to the sacrificial grain orientation of the graphite nodules following asperity removal in the wear region from cylinder liner tribo-element. The average value of $\mathrm{COF}$ obtained is 0.16 . This exhaust of nodular graphite could have initiated the partial In-situ solid lubrication and hence limiting the frictional force. When the normal Load is increased to $40 \mathrm{~N}$, a substantial increment in the COF can be seen from the beginning of the test to the conclusion with average COF of 0.32 . The frictional state is unsteady with continuous fluctuations above and below the mean line. Dry sliding tribotests at a normal load of $60 \mathrm{~N}$ exhibits the highest average COF value of 0.38 with an unsteady frictional state and fluctuations of largest amplitude over mean COF line. After the exhaust of nodular graphite, the increasing area of contact due to exorbitant normal load leads to the removal of fresh surface asperities and hence influencing the frictional characteristic [26].

\subsection{Wear}

All the tribo-tested specimens were ultrasonically rinsed with acetone and wiped dry before proceeding for microscopic and profilometric investigations. 3D profilometry with standard repeatability was used to measure wear volume by the wear scar area integration of 16 parallel profiles accessed using the scar depth at an optical resolution of 70 as shown in Fig. 11. Non-contact optical surface profilometry with repeatability was conducted prior to and after tribotests. Average surface roughness $\left(R_{\mathrm{a}}\right)$ of $0.18 \mu \mathrm{m}$ prior to the tribo-testing was observed for chromium coating overlay of the piston ring while as the $R_{\mathrm{a}}$ valve of liner conjugate obtained was $0.92 \mu \mathrm{m}$. Post tribo-testing there was a substantial decrease in the Ra values of both piston ring and liner surfaces. $R_{\mathrm{a}}$ values of $0.12 \mu \mathrm{m}$ and 0.48 $\mu \mathrm{m}$ were observed for piston ring and cylinder liner surfaces respectively. The decrement in the $R_{\mathrm{a}}$ values post tribo-testing can be attributed to topmost asperity wearing and filling of the surface depressions with wear debris. Wear of tribo-conjugates was calculated, in terms, of specific wear coefficient (Kw), which is obtained by Archard's Wear Model equation [27]: 


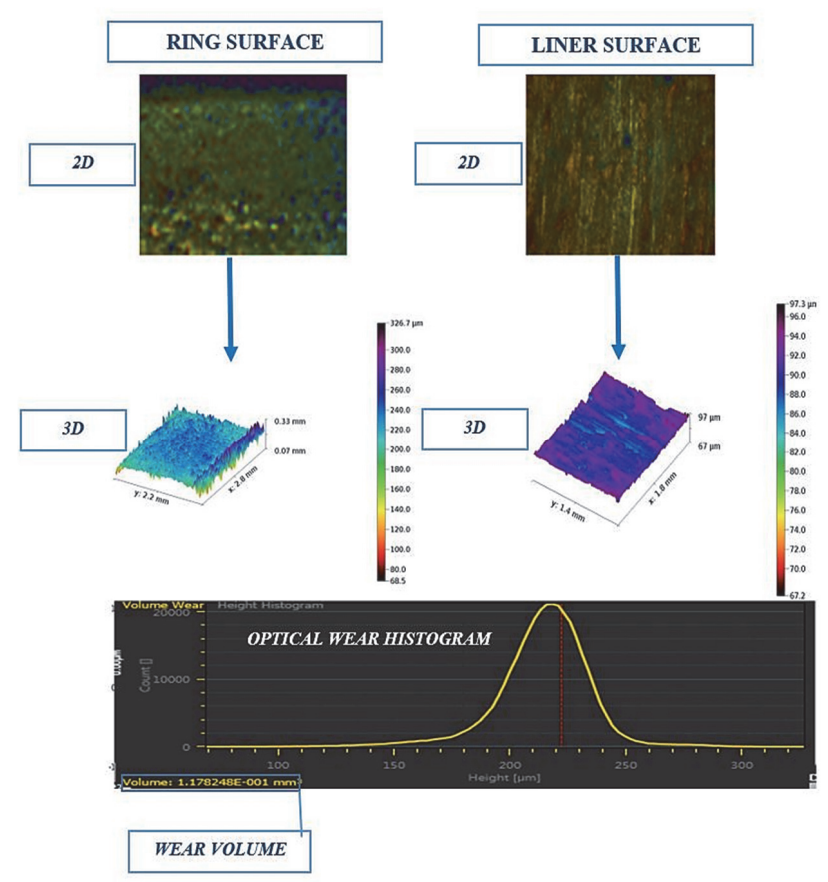

Fig. 11 R.tec 3D profilometry of wear tracks of ring and liner specimens with optical wear histogram

$$
K_{w}=\frac{V_{w}}{D_{s} P}
$$

\section{Nomenclature}

$K_{w}=$ Specific Wear Coefficient $\left(\mathrm{mm}^{3} / \mathrm{Nm}\right), V_{w}=$ Wear Volume $\left(\mathrm{mm}^{3}\right), D_{s}=$ Sliding Distance $(\mathrm{m}), P=\operatorname{Normal}$ load $(\mathrm{N})$

Wear coefficients as a function of cumulative time are shown in Fig. 12. Dry sliding of the tribo-conjugate showed sharp ridges in the wear tracks that extruded off the surface under starved lubrication sliding. A gradual increment in wear volumes with the increase in normal load is observed. Obtained wear coefficient values are in the order of 2.2-3.5 $\times 10^{-4}$ $\mathrm{mm}^{3} / \mathrm{Nm}$ for cylinder liner with a mean value of $10.5 \mu \mathrm{m}$ and as such it can be inferred that this is possibly due to topmost asperity wearing subjected to load increments. Optical wear histogram showed in $4.3 \mu \mathrm{m}$ (mean value) of wear volume for chromium coating with Wear coefficient in a range of 1.87-2.8

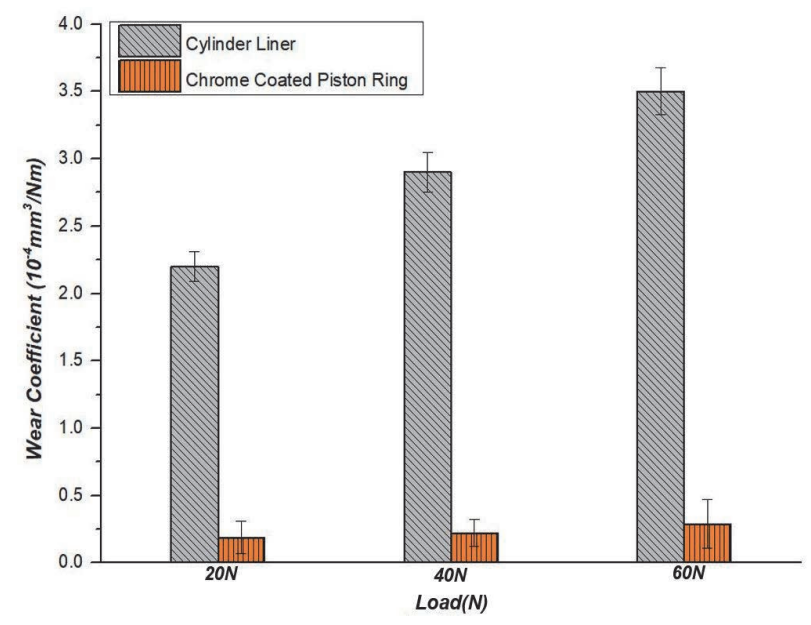

Fig. 12 Obtained wear coefficients as a function of normal load $\times 10^{-5} \mathrm{~mm}^{3} / \mathrm{Nm}$. It is concluded that the substantial difference in the hardness and other mechanical properties of the triboelements in conjunction with the chromium coating ascribed superior wear characteristics, while the cylinder liner showed catastrophic wear characteristics under lubricant starvation [28]

\section{Surface analysis}

SEM analysis was carried out through all the cylinder liner and piston ring specimens tested for lubrication drought with dry sliding under variable normal loads. The worn-out surface morphology and relevant surface micrographs are discussed below.

Figure 13 shows SEM micrographs of cylinder liner specimens nearly simulation tested for lubrication drought under varying loads. Figures $13(\mathrm{a}-\mathrm{c})$ correspond to SEM micrographs at 500x magnification while Figs. 13(a1-c1) are corresponding SEM micrographs at higher magnification of 1000x. It can be observed that with increment in load under in situ sliding conditions, there is a substantial increase in surface deterioration. At a lower load of $20 \mathrm{~N}$, the tendency of shallow groove and pit formation is considerably lower. The initiation of delamination fracture is evidently visible with the removal of a thin layer of surface material. With increased load, the surface damage in the form of shallow grooves, parallel channel grooves, and delamination induced material removal is observed along the sliding direction. Similar wear behaviour has been observed by Susan et. Al [29]. Further load increment accounts for complete dislodging of surface material in the form of delaminated sheets with a significant reduction in groove and pit formation. This stage of loading under lubrication drought exhibits the formation of crevices with similar surface deteriorations evidenced in the research work of Gara et. al [30]. The surface failures have been reported previously by various researchers and as such a strong need for surface mending by a bonafide lubrication system arises.

Surface characterization by SEM was further assisted by an integrated EDX analyser to evaluate the surface synergies, tribochemistry, and lubrication mechanisms if any. The elemental characterization of the mating surfaces in dry sliding conditions was provided by EDX analyser. This helps in evaluating the material transfer followed by different wear mechanisms. Figure 14 illustrates the elemental spectra of wear tracks tested tribo-elements under dry sliding. It was expected that the elemental peaks of parent constituent elements would show on the EDX spectra of wear zone, but alien elemental concentration spectral peaks of $\mathrm{Cr}$ confirm the surface material transfer from the counterpart ring specimen resulting in surface deterioration. This can be ascribed to abrasive scratches and coating peel. Further, the presence of elemental carbon (C) confirms the subsurface graphitization in the ferrous matrix. Elemental iron and chromium with oxygen confirm the formation of sacrificial $\mathrm{Cr}_{2} \mathrm{O}_{3}$ and $\mathrm{Fe}_{2} \mathrm{O}_{3}$ tribofilms [31]. However, the adhesion and shear strength of these tribo-films couldn't withstand the normal load, reciprocating shear and hardness gradient [32]. The adhered wear debris is a consequence of material transfer from conjugate chromium coating on piston ring specimen.

Given all this, it is confirmed that there is prominent fresh surface exposure to oxidation wear. The involvement of graphite flakes in providing partial in-situ solid lubrication aid is well demonstrated, which is the inherent material characteristic of grey CI cylinder liner. The dominant wear mechanisms identified are plastic stage delamination, adhesive 

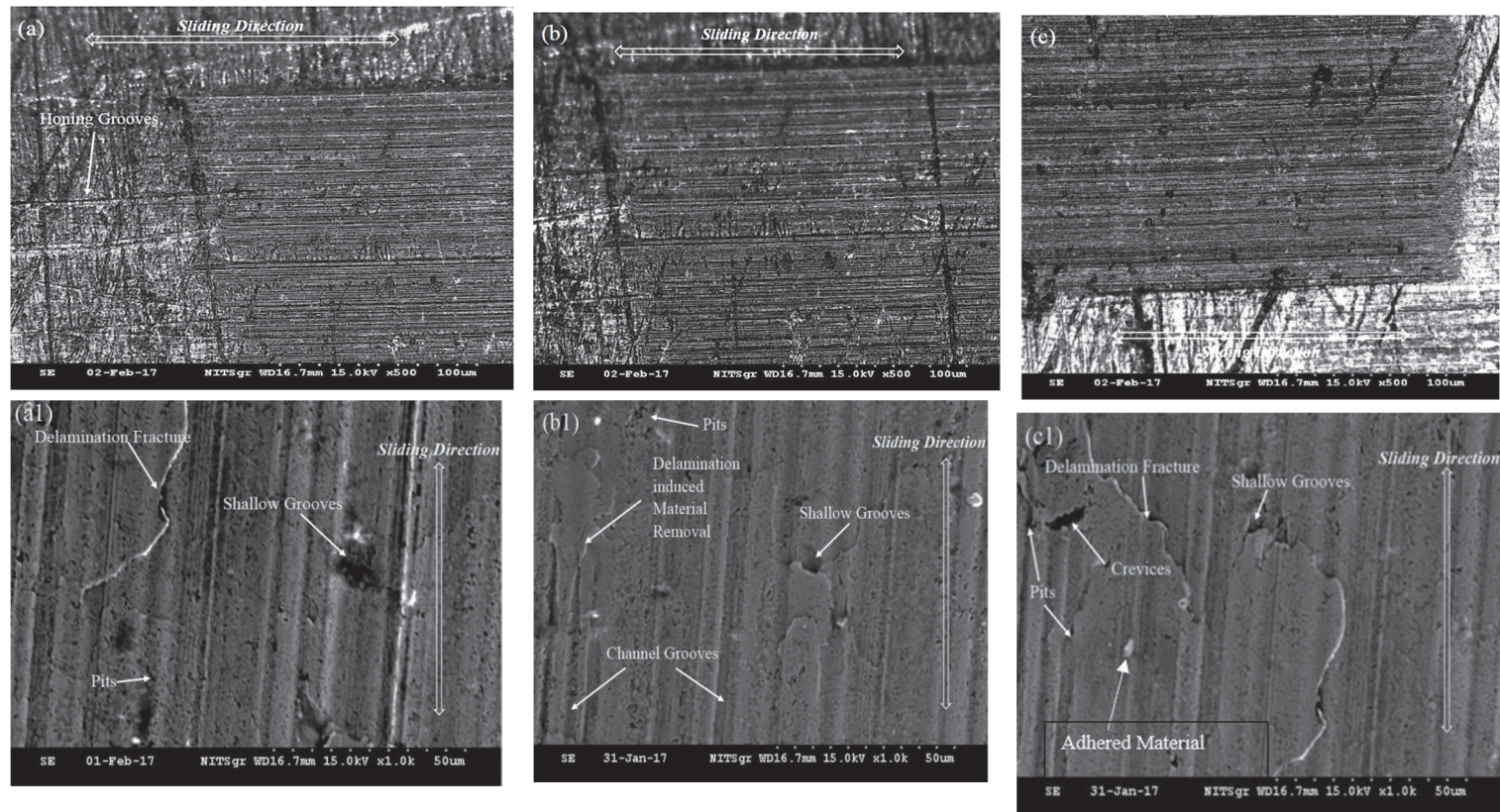

Fig. 13 SEM micrographs of worn out cylinder liner tested at (a) Load of 20 N 500x, (a1) load of 20 N 1000x, (b) Load of 40 N 500x, (b1) Load of 40 N 1000x, (c) Load of 60 N 500x, (c1) Load of 60 N 1000x
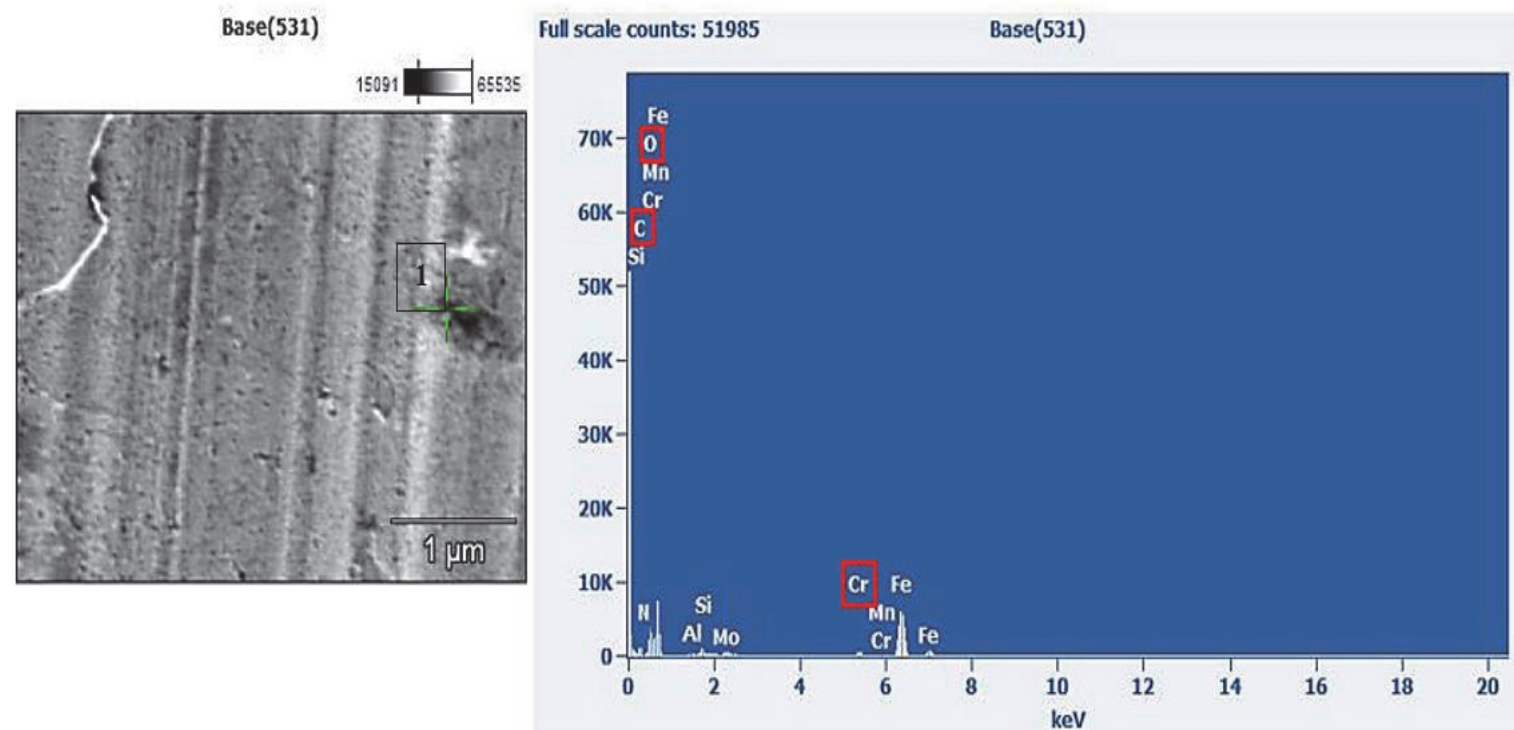

Fig. 14 EDX elemental spectra of cylinder liner specimen tested with PAO10 base oil

wear, abrasive wear, and surface oxidation and the similar wear mechanisms been reported in various research works [33-35].

\section{Conclusions}

The tribological characteristics of wear rates, Coefficient of Friction, the formation of sacrificial tribofilms was evaluated under dry sliding bench tests simulating lubrication starvation. Wear volumes were quantified with optical microscopy while as the surface synergies and tribochemistry were investigated with EDX integrated into SEM. On the basis of repeatability of tribotests major conclusions inferred are enlisted below:

1. Grey CI surface coating demonstrated the surface delamination and scuffing failure in lubrication drought, contrasting the coating performance in terms of scuffing proximity and resistance to surface deterioration.
2. Catastrophic wear rates and un-stabilized surface attributes, in terms of average roughness and COF, are the characteristic of the tribo-conjugation. in lubrication starvation.

3. The extrusion-initiated peeling of the surface in the form of delaminated sheets resulted in the exposure of sub-surface graphitic zones on cylinder liner surface which assisted in stabilizing COF by partial in-situ solid lubrication during dry sliding of conjunction.

4. The catastrophism in terms of intensive cylinder liner surface wear is an attribute of the hardness gradient between the tribo-elements. The HV values exhibited by chromium coating are approximately 4 times to the corresponding HV values of cylinder liner. In a broader spectrum, mechanical attributes of grey CI liner need to be improved. 
5. The prime failure modes in this research study are scuffing, stick and slip failure, abrasion, adhesion, and oxidation wear failures. The high-temperature test condition could have initiated the wear debris welding followed by abrasion in successive strokes of tribotests. This is evidenced by the channel ploughing action by wear debris rolling.

6. With stepped load increments, approximately $50 \%$ frictional increase relative to first increment of $20 \mathrm{~N}$ was observed which further increased to approximately $58 \%$ in the next step load of $40 \mathrm{~N}$. This is an indicative of surface failures under stepped loads and is demonstrated in the SEM micrographs. Further, the chromium coated piston ring specimens showed approximately 59\% less wear volume relative to the cylinder liner specimens, which shows the material superiority of chromium coating over bulk grey cast iron.

\section{References}

[1] Chen, G., Bedapudi, P. and Flynn, P. L., "Investigation of Inlet Condition Effects on Outputs and Exhaust Emissions of High-Power Medium-Speed Diesel Engines," Proceedings of ASME, 2003, 107114.

[2] Mazuro, P. and Teodorczyk, A., "EC1-2: Mechanical Efficiency and Losses of Internal Combustion Engines with Cylinder Axes Parallel to Drive Shaft Axis(EC: Engines and Engine Components, General Session Papers)," COMODIA, 7, 2008, 861-868

[3] Kfoury, G. A. and Chalhoub, N. G., "Computation of the Instantaneous Frictional Losses of Internal Combustion Engine Components," Proceedings of ASME, 2010, 679-686.

[4] Olander, P., Hollman, P. and Jacobson, S., "Piston Ring and Cylinder Liner Wear Aggravation Caused by Transition to Greener Ship Transports-Comparison of Samples from Test Rig and Field," Wear, 302, 1-2, 2013, 1345-1350.

[5] John, A. P. and Agarwal, V. K., “Optimization of Piston Skirt Profile Design to Eliminate Scuffing and Seizure in a Water Cooled Gasoline Engine," SAE Technical Paper, 2015-01-1726, 2015.

[6] Shuster, M. M., Stong, T., Deis, M. C. and Burke, D. C., "Piston Ring Cylinder Liner Scuffing Phenomenon: Investigation, Simulation and Prevention," SAE 1999 International Congress and Exposition, SAE Technical Paper, 1999-01-1219, 1999.

[7] Enthoven, J. C., Cann, P. M. and Spikes, H. A., "Temperature and Scuffing," Tribology Transactions, 36, 2, 1993, 258-266.

[8] Wong, T. Y., Scott, C. G. and Ripple, D. E., "Diesel Engine Piston Scuffing: A Preliminary Investigation," SAE, Warrendale, PA., SAE Paper, 930687, 1993.

[9] Barrell, D. J. W., Priest, M. and Taylor, C. M., "Bench Test Study of Piston Ring Flank and Piston Groove Interaction," In Lubrication at the Frontier: The Role of the Interface and Surface Layers in the Thin Film and Boundary Regime, Elsevier Science B. V, 1999, 343-351.

[10] Ludema, K. C., "A Review of Scuffing and Running-in of Lubricated Surfaces, with Asperities and Oxides in Perspective," Wear, 100, 1-3, 1984, 315-331.

[11] Knopf, M., Eiglmeier, C. and Merker, G. P., "Calculation of Unsteady Hydrodynamic Lubrication and Surface Contact at the Piston-Ring / Cylinder-Liner Interface," SAE Technical Paper, 981402, 1998.

[12] Yoon, K. -K., Kim, W. -B. and Na, S. -J., "Shape Deformation of a Piston Ring Groove by Laser Surface Hardening," Surface and Coatings Technology, 78, 1-3, 1996, 157-167.

[13] Ezhilmaran, V., Vasa, N. J. and Vijayaraghavan, L., “Investigation on Generation of Laser Assisted Dimples on Piston Ring Surface and Influence of Dimple Parameters on Friction," Surface and Coatings
Technology, 335, 2018, 314-326.

[14] Lin, J., Wei, R., Bitsis, D. C. and Lee, P. M., “Development and Evaluation of Low Friction TiSiCN Nanocomposite Coatings for Piston Ring Applications," Surface and Coatings Technology, 298, 2016, 121-131.

[15] Tirupataiah, Y. and Sundararajan, G., "Evaluation of Microhardness Correction Procedures," Wear, 110, 2, 1986, 183-202.

[16] Glazov, V. M. and Vigdorovich, V. N., “Use of the Microhardness Method in Studying the Phase Diagrams and Structures of ThreeComponent Alloys," Springer, Consultants Bureau, 1971, 91-119.

[17] Kaleicheva, J., Mishev, V., Karaguiozova, Z., Nikolcheva, G. and Miteva, A., "Effect of Nanoadditives on the Wear Behavior of Spheroidal Graphite Cast Irons," Tribology in Industry, 39, 3, 2017, 294-301.

[18] Wei, R. P., “Corrosion Fatigue of Iron-Chromium-Nickel Alloys: Fracture Mechanics, Microstructure and Chemistry," The U. S. Department of Energy, DE-FG02-88ER45354, 1992.

[19] Obara, R. B., Faria, J. O. M. G. and Sinatora, A., "The Effect of Oxide and Tribofilm Formation on the Wear of Cylinder Bores from FlexFuel Engines," SAE Technical Paper, 2016-36-0277, 2016.

[20] Harding, W. B., "Testing of Metallic and Inorganic Coatings," Philadelphia, PA: ASTM International, 1987, 177-192.

[21] Brown, L. M., "Indentation Size Effect and the Hall-Petch 'Law'," Materials Science Forum, 662, 2011, 13-26.

[22] Sangwal, K., Kothari, A. and Arora, S. K., "Formation of Indentation Cracks and Origin of Indentation Size Effect in Cadmium Tartrate Pentahydrate Single Crystals," Surface Science, 600, 7, 2006, 14751486.

[23] Marcinkowski, M. J. and Lipsitt, H. A., "The Plastic Deformation of Chromium at Low Temperatures," Acta Metallurgica, 10, 2, 1962, 95-111.

[24] Bayer, R. G., “Mechanical Wear Fundamentals and Testing, Revised and Expanded," CRC Press, 2004.

[25] Plint, A. G., "Friction Force Measurement in Reciprocating Tribometers," STLE, 2011.

[26] Singer, I. L. and Pollock, H. M., "Fundamentals of Friction: Macroscopic and Microscopic Processes," Dordrecht: Springer Science \& Business Media, 1992.

[27] Totten, G. E., "Friction, Lubrication, and Wear Technology," ASM Handbook, ASM International, USA, 18, 1992.

[28] Krushchov, M. M. and Babichev, M. A., "The Connection between Hardness under Compression and Hardness during Abrasion in Metals and Minerals. (in Russian)," Wear, 1, 3, 1957, 260.

[29] Hartfield-Wünsch, S. E., Tung, S. C. and Rivard, C. J., “Development of a Bench Wear Test for the Evaluation of Engine Cylinder Components and the Correlation with Engine Test Results," SAE Technical Paper, 932693, 1993.

[30] Gara, L., Zou, Q., Sangeorzan, B., Barber, G., McCormick, H. and Mekari, M. H., "Wear Measurement of the Cylinder Liner of a Single Cylinder Diesel Engine Using a Replication Method," Wear, 268, 3-4, 2010, 558-564.

[31] Domka, F., Basińska, A., Przystajko, W. and Fiedorow, R., "Surface Chemistry of $\mathrm{Fe}_{2} \mathrm{O}_{3}-\mathrm{Cr}_{2} \mathrm{O}_{3}$ and $\mathrm{Fe}_{2} \mathrm{O}_{3}$ Catalysts," Surface Technology, 21, 2, 1984, 101-108.

[32] Cha, S. C. and Erdemir, A., "Coating Technology for Vehicle Applications," Springer, 2015, 25-35.

[33] Mudradi, S., "Dry Sliding Wear Behavior of Cast Iron Powder Filled Epoxy Composites," AIP Conference Proceedings, 2080, 1, 2019, 020020.

[34] Takeuchi, E., "The Mechanisms of Wear of Cast Iron in Dry Sliding," Wear, 11, 3, 1968, 201-212.

[35] Takeuchi, E., "The Mechanism of Wear of Spheroidal Graphite Cast Iron in Dry Sliding," Wear, 19, 3, 1972, 267-276. 